\title{
PREDIÇÃO DE VALORES GENÉTICOS ADITIVOS NA SELEÇÃO VISANDO OBTER CULTIVARES DE CAFÉ MAIS RESISTENTES À FERRUGEM. $\left({ }^{1}\right)$
}

\author{
MARCOS RAFAEL PETEK $\left({ }^{2 *}\right)$; TUMORU SERA $\left({ }^{3}\right)$; INÊS CRISTINA DE BATISTA FONSECA $\left({ }^{4}\right)$
}

\begin{abstract}
RESUMO
O objetivo do trabalho foi estimar parâmetros genéticos e predizer os valores genéticos aditivos na seleção de progênies $\mathrm{F}_{2}$ de Coffea arabica ("Sarchimor" x ("Icatu" x "Catuaí")) com mais de cinco genes de resistência à ferrugem. Foram utilizadas 27 progênies derivadas do cruzamento "Sarchimor" PR 751637 x ("Icatu" x "Catuaí") MRFPB-C-41-1 e a testemunha 'IAPAR 59'. Os caracteres avaliados foram os seguintes: vigor vegetativo, resistência à ferrugem, tamanho de grãos, época de maturação dos frutos e produtividade. A seleção foi realizada a partir do efeito genético aditivo individual para vigor vegetativo e resistência à ferrugem, predito pela metodologia REML/BLUP, que foram os caracteres com variabilidade. O ganho genético aditivo com a seleção de 54 indivíduos (10\% de intensidade de seleção) foi de 3,14\% para vigor vegetativo e 10,29\% para resistência à ferrugem. Concluiu-se que a partir desta população é possível a obtenção de linhagens superiores com resistência à ferrugem e alto vigor vegetativo e que a seleção de plantas individuais a partir de efeito genético aditivo facilita a escolha dos indivíduos geneticamente superiores, maximizando o ganho genético por ciclo de seleção.
\end{abstract}

Palavras-chave: Coffea arabica, melhoramento genético, vigor vegetativo, resistência à ferrugem, seleção antecipada, modelos mistos.

\section{ABSTRACT \\ PREDICTION OF GENETIC ADDITIVE VALUES FOR DEVELOPMENT OF A COFFEE CULTIVAR WITH INCREASED RUST RESISTANCE}

The aim of this research was to estimate genetic parameters and predict the additive genetic values in the selection of Coffea arabica progenies ("Sarchimor " $\mathrm{x}$ ("Icatu" x "Catuaí")) carrying more than five rust resistance genes. The research was carried out with $27 \mathrm{~F}_{2}$ progenies derived from "Sarchimor " $\mathrm{PR}$ 75163-7 x ("Icatu " x "Catuaí") MRFPB-C-41-1 and the control 'IAPAR 59 '. The traits evaluated were vegetative vigor, rust resistance, bean size, fruit maturity and productivity. The selection was based on individual additive genetic effect for vegetative vigor and resistance to rust, characters that presented variability. The additive genetic gains with the 54 individuals plants selected $(10 \%$ of selection intensity) were $3,1 \%$ for vegetative vigor and $10,3 \%$ for rust resistance. It is possible to obtain superior inbred lines with rust resistance and high vegetative vigor from this population. The selection of individual plants with additive genetic effects promotes the identification of genetically better individuals, and the maximization of the genetic per selection cycle.

Key words: Coffea arabica, breeding, vegetative vigor, rust resistance, anticipated selection, mixed models.

$\left({ }^{1}\right)$ Recebido para publicação em 26 de março de 2007 e aceito em 5 de julho de 2007.

$\left({ }^{2}\right)$ Instituto Agronômico de Campinas, Centro de Café Alcides Carvalho, Avenida Barão de Itapura, 1481, Caixa Postal 28, 13001-970Campinas (SP). E-mail: mrpetek@iac.sp.gov.br. $\left(^{*}\right)$ Autor correspondente.

$\left({ }^{3}\right)$ Instituto Agronômico do Paraná, Área de genética e Melhoramento de Café, Caixa Postal 481, 86047-902 Londrina (PR). E-mail: tsera@iapar.br.

(4) Universidade Estadual de Londrina, Centro de Ciências Agrárias, Departamento de Agronomia, Caixa Postal 6001, 86051-990 Londrina (PR). E-mail: inescbf@uel.br. 


\section{INTRODUÇÃO}

O desenvolvimento de uma cafeicultura brasileira mais sustentável passa pelo aumento da rentabilidade do produtor, bem como sua permanência na atividade depende de sistemas de cultivo estáveis que proporcionem maior longevidade para as lavouras. Cultivares produtivas e possuidoras de características adaptativas a cada sistema de cultivo são um dos principais componentes da sustentabilidade.

As cultivares brasileiras são altamente produtivas e levando em consideração a estreita base genética existente em Coffea arabica, a possibilidade de ganhos efetivos em produtividade de grãos é bastante reduzida dentro dos programas de melhoramento (FAzuoli et al., 2002). Além dessa dificuldade em se obter progresso genético em produtividade, a C. arabica como planta perene possui período juvenil e acentuada oscilação anual de produção, sendo necessários vários anos para avaliar a precocidade e longevidade produtiva e realizar a seleção (SERA, 2001). Portanto, considerando-se todas estas dificuldades do melhoramento genético de café, é de fundamental importância utilizar características auxiliares nos processos de seleção que direta ou indiretamente aumentem a produtividade de grãos. Também se recomenda utilizar metodologias de experimentação e análise dos dados que permitam o máximo de eficiência em cada geração de seleção.

O desenvolvimento de cultivares resistentes e/ ou tolerantes às pragas e doenças tem papel importante no aumento de produtividade e diminuição de custos de produção. Mesmo que haja defensivos para o controle, a aplicação pode não ser eficiente e o uso de cultivares resistentes é o método de controle mais eficiente e de menor custo, além de evitar a contaminação do ambiente e de trabalhadores rurais. A ferrugem-alaranjada causada por Hemileia vastatrix é a principal doença da cafeicultura em abrangência e danos. Apesar de já existirem cultivares resistentes à ferrugem disponíveis no mercado (Fazuoli et al., 2002; Sera et al., 2002; Pereira et al., 2002), é preciso contínuo trabalho de seleção de progênies. Segundo VÁrzea et al., (2002), a durabilidade da resistência das cultivares atuais é difícil de ser prevista.

Uma das estratégias utilizadas pelos programas de melhoramento de café do Brasil é o acúmulo de genes de resistência qualitativa, presentes nos materiais derivados de "Híbrido de Timor", conjuntamente com genes de efeitos quantitativos presentes, por exemplo, em linhagens do "Icatu" (VÁrzea et al., 2005; FAzUoli et al., 2005; SERA et al., 2005), bem como em materiais derivados do "Híbrido de Timor" (Pereira et al., 2005). Outra fonte de resistência utilizada são os materiais possuidores do fator $\mathrm{SH}_{3}$ originário de Coffea liberica que possui efeito qualitativo, mas existem também evidências que este fator é acompanhado por outros genes que conferem resistência horizontal (VÁRzEA et al., 2002).

Selecionar materiais com maior vigor vegetativo também é uma estratégia que aumenta a produtividade de cultivares (SEvERINo et al., 2002), pois indica maior eficiência em absorver nutrientes e é menos vulnerável às condições edafoclimáticas desfavoráveis (PетеK et al., 2002). Outra característica que está relacionada com a produtividade é o tamanho dos grãos que proporciona maior rendimento na secagem e no beneficiamento (FAZUOLI, 1977).

Devido às particularidades do café como cultura perene, o procedimento analítico padrão recomendado para os estudos em genética quantitativa e também para a prática de seleção é o REML/BLUP. Este procedimento permite a estimação dos componentes de variância por máxima verossimilhança restrita (REML) e a predição de valores genéticos pela melhor predição linear não viciada (BLUP) (RESENDE et al., 2001; RESENDE, 2002).

Esta metodologia tem sido utilizada para a seleção em diversas culturas perenes como o Pinus (Missio et al., 2004), eucalipto (GARCIA et al., 2005) e pupunha (FARIAS Neto e RESENDE, 2001), por exemplo. Outra justificativa para a utilização desta metodologia de modelos mistos é a estimativa de herdabilidades e efeitos genéticos aditivos individuais que em café não é comum de ser realizado (Resende et al., 2001). Portanto, considerando que o objetivo na seleção em C. arabica é a obtenção de cultivares do tipo linhagem e a seleção é realizada em plantas individuais dentro de progênies, a predição do valor genético aditivo de cada individuo levará à maximização da possibilidade de selecionar o melhor entre dois indivíduos e, conseqüentemente, a maximização do ganho genético por ciclo de seleção que são propriedades dos preditores BLUP (RESENDE, 2002).

O objetivo deste trabalho foi estimar parâmetros genéticos e predizer os valores genéticos aditivos a partir da metodologia REML/BLUP na seleção de progênies de Coffea arabica ("Sarchimor" x ("Icatu" x 'Catuaí')) possuidores de maior vigor vegetativo e resistência à ferrugem.

\section{MATERIAL E MÉTODOS}

O experimento foi instalado em solo do tipo Latossolo Vermelho Distrófico, no Centro de Produção e Experimentação de Londrina do Instituto 
Agronômico do Paraná, com temperatura média anual de $20,8{ }^{\circ} \mathrm{C}, 585 \mathrm{~m}$ de altitude, latitude $23^{\circ} 22^{\prime} \mathrm{S}$ e longitude $51^{\circ} 10^{\prime} \mathrm{W}$. O delineamento experimental utilizado foi em blocos ao acaso, com duas repetições, 27 progênies (tratamentos) e 10 plantas/parcela no espaçamento de $2,5 \times 0,5$ metros.

\section{Material Genético}

As 27 progênies $F_{2}$ deste experimento são derivadas do cruzamento "Sarchimor" PR 75163-7 x ("Icatu" x "Catuaí") MRFPB-C-41-1 na segunda geração de autofecundação e a testemunha 'IAPAR $59^{\prime}$. Como essas progênies estão em $F_{2}$, obtidas por autofecundação, foram consideradas como famílias $\mathrm{S}_{1}$ para fins de estimação e predição de parâmetros genéticos, pois, devido à sua constituição genética em que os parentais não são homozigotos, espera-se comportamento similar a progênies de autofecundação $\left(\mathrm{S}_{1}\right)$ de plantas alógamas. Assim, para os cálculos das variâncias genéticas aditivas considera-se $66,6 \%$ da variabilidade entre e $33,3 \%$ dentro de progênies, ou seja 1 entre progênies e 1/2 dentro de progênies.

\section{Caracteres Avaliados}

$\mathrm{O}$ vigor vegetativo $(\mathrm{V})$ de cada planta foi avaliado antes da produção em 2000 (V00) e em 2002 e 2003 depois de as plantas receberem poda de recepa após a geada de 2000. Cada planta foi avaliada segundo uma escala de 1 a 10 , sendo: 1 = planta pequena e amarela com abundante seca de ramos e 10 = planta normal e verde escura com abundante ramificação.

A resistência à ferrugem $(\mathrm{F})$ foi avaliada segundo uma escala de notas variando de 1 a 5 , sendo: $1=$ ausência de pústulas e reações de hipersensibilidade; 2 = poucas folhas com pústulas sem esporos e com reações de hipersensibilidade; $3=$ poucas pústulas por folha com alta produção de esporos e pouco distribuídas; 4 = média quantidade de pústulas por folha, distribuídas na planta com alta produção de esporos; $5=$ alta quantidade de pústulas com alta produção de esporos e alta desfolha da planta. Porém, para facilitar a interpretação dos resultados das predições, a escala foi invertida. Nenhum tratamento fitossanitário foi realizado no experimento.

O tamanho dos grãos (TG) foi avaliado atribuindo-lhes notas de 1 a 5 utilizando cultivares comerciais de tamanho de grãos conhecidos como padrão, sendo: $1=$ (muito pequena) semelhante a 'Mokka', 2 = (pequena) semelhante a 'Icatu Precoce IAC $3282^{\prime}, 3=$ (média) semelhante a 'Catuaí Vermelho IAC $81^{\prime}, 4=$ (grande) semelhante a 'Mundo Novo IAC
$375-4$ e $5=$ (muito grande) semelhante a 'Maragogipe'.

Cada planta foi classificada quanto à época de maturação dos frutos (M) em: tardia, semitardia, média, semiprecoce e precoce, atribuindo-lhes, respectivamente, as notas 1, 2, 3, 4 e 5 .

O potencial de produtividade de cada planta foi avaliado em litros de fruto cereja/ planta, por meio de avaliação visual, levando-se em consideração o tamanho dos grãos, número de frutos/roseta e ramificação da planta. A produção em litros de fruto cereja/planta foi transformada para produtividade/ ha $(\mathrm{P})$ por meio da expressão: $\mathrm{P}=[(8000 \mathrm{pl} / \mathrm{ha} \mathrm{x}$ litros/planta) / 500].

Os caracteres vigor vegetativo, tamanho dos grãos, maturação dos frutos e potencial de produtividade de grãos foram avaliados antes da colheita em 2000, 2002 e 2003 sendo considerado a média como o caráter. A resistência à ferrugem foi avaliada antes da colheita em 2000 e 2002, porém utilizada como caráter apenas a avaliação de 2002, visto que em 2000, a incidência da doença foi menor.

\section{Análise dos Dados}

O programa SELEGEN - REML/BLUP (Seleção Genética Computadorizada) (RESENDE, 2006) foi utilizado para estimação dos parâmetros e predição dos valores genéticos. O procedimento adotado pelo programa para a predição dos valores genéticos é o BLUP (melhor predição linear não viciada) ou modelos mistos, utilizando estimativas de variância obtidas pelo método REML (máxima verossimilhança restrita) descritos por RESENDE (2002).

O Modelo Linear Misto aplicado ao delineamento em blocos ao acaso, considerando progênies de autofecundação $\left(\mathrm{S}_{1}\right)$, com 10 plantas/ parcela e uma medida por individuo é descrito por Resende (2002) como:

$$
y=X b+Z a+W c+e
$$

em que: $y, b, a, c$ e $e$ são vetores de dados, dos efeitos de blocos (fixos), dos efeitos genéticos aditivos (aleatórios), de efeitos de parcela (aleatório) e dos erros (aleatórios), respectivamente.

$X, Z$ e $W$ são matrizes de incidência para $b, a$ e $c$ respectivamente. variâncias:

Distribuição e estrutura de médias e

$$
\begin{aligned}
& y \mid b, V \sim N(X b, V) \\
& a \mid A, \sigma_{a}^{2} \sim N\left(0, A \sigma_{a}^{2}\right) \\
& c \mid \sigma_{c}^{2} \sim N\left(0, I \sigma_{c}^{2}\right)
\end{aligned}
$$




$$
e \sigma_{e}^{2} \sim N\left(0, I \sigma_{e}^{2}\right)
$$

$\operatorname{Cov}\left(\mathrm{a}, \mathrm{c}^{\prime}\right)=0 ; \operatorname{Cov}\left(\mathrm{a}, \mathrm{e}^{\prime}\right)=0 ; \operatorname{Cov}\left(\mathrm{c}, \mathrm{e}^{\prime}\right)=0$

Ou seja:

$\mathrm{E}\left[\begin{array}{l}y \\ a \\ c \\ e\end{array}\right]=\left[\begin{array}{l}X b \\ 0 \\ 0 \\ 0\end{array}\right]$ e $\operatorname{Var}\left[\begin{array}{l}y \\ a \\ c \\ e\end{array}\right]=\left[\begin{array}{cccc}V & Z G & W C & R \\ G Z, & G & 0 & 0 \\ C W & 0 & C & 0 \\ R & 0 & 0 & R\end{array}\right]$

em que:

$$
\begin{aligned}
& \mathrm{G}=\mathrm{A} \hat{\sigma}_{a}^{2} \\
& \mathrm{R}=\mathrm{I} \hat{\sigma}_{c}^{2} \\
& \mathrm{C}=\mathrm{I} \hat{\sigma}_{e}^{2} \\
& \mathrm{~V}=\mathrm{ZA} \hat{\sigma}_{a}^{2} \mathrm{Z}^{\prime}+\mathrm{WI} \hat{\sigma}_{c}^{2} \mathrm{~W}^{\prime}+\mathrm{I} \hat{\sigma}_{e}^{2}=\mathrm{ZGZ}+
\end{aligned}
$$

$\mathrm{WCW}^{\prime}+\mathrm{R}$

Equações de modelo misto

$$
\begin{aligned}
& {\left[\begin{array}{ccc}
X^{\prime} X & X^{\prime} Z & X^{\prime} W \\
Z^{\prime} X & Z^{\prime} Z+A^{-1} \lambda_{1} & Z^{\prime} W \\
W^{\prime} X & W^{\prime} Z & W{ }^{\prime} W+I \lambda_{2}
\end{array}\right]\left[\begin{array}{l}
\hat{b} \\
\hat{a} \\
\hat{c}
\end{array}\right]=\left[\begin{array}{l}
X^{\prime} y \\
Z^{\prime} y \\
W^{\prime} y
\end{array}\right] \text { em que: }} \\
& \lambda_{1}=\frac{\hat{\sigma}_{e}^{2}}{\hat{\sigma}_{a}^{2}}=\frac{1-\hat{h}^{2}-\hat{c}^{2}}{\hat{h}^{2}} ; \lambda_{2}=\frac{\hat{\sigma}_{e}^{2}}{\hat{\sigma}_{c}^{2}}=\frac{1-\hat{h}^{2}-\hat{c}^{2}}{\hat{c}^{2}} \\
& \hat{h}^{2}=\frac{\hat{\sigma}_{a}^{2}}{\hat{\sigma}_{a}^{2}+\hat{\sigma}_{c}^{2}+\hat{\sigma}_{e}^{2}}: \text { herdabilidade individual no }
\end{aligned}
$$

sentido restrito no bloco.

$$
\hat{c}^{2}=\hat{\sigma}_{c}^{2} /\left(\hat{\sigma}_{a}^{2}+\hat{\sigma}_{c}^{2}+\hat{\sigma}_{e}^{2}\right) \text { correlação devida ao }
$$

ambiente comum da parcela.

$\hat{\sigma}_{a}^{2}$ : variância genética aditiva.

$\hat{\sigma}_{c}^{2}$ : variância entre parcelas.

$\hat{\sigma}_{e}^{2}$ : variância residual (ambiental dentro de parcelas + não aditiva).

A: matriz de correlação genética aditiva entre os indivíduos em avaliação.

Para o caso de experimento balanceado, as soluções obtidas para efeito genético aditivo (â) a partir das equações de modelo misto equivalem às predições obtidas pelo índice multiefeitos (RESENDE e HigA, 1994, citado por RESENDE, 2002), dado por: , em que:

$$
I=b_{1}\left(Y_{i j k}-\bar{Y}_{i j .}\right)+b_{2}\left(\bar{Y}_{i . .}-\bar{Y}_{\ldots}\right)+b_{3}\left(\bar{Y}_{i j .}-\bar{Y}_{i . .}-\bar{Y}_{. j .}+\bar{Y}_{\ldots}\right)
$$

$$
\begin{gathered}
b_{1}=\frac{\left(1,5-\rho_{a}\right) \hat{\sigma}_{a}^{2}}{\hat{\sigma}_{d p}^{2}} ; b_{2}=\frac{\frac{\left[1,5+(n b-1) p_{a}\right]}{\hat{\sigma}_{f a}^{2}+\hat{\sigma}_{c}^{2} / b+\hat{\sigma}_{d p}^{2} / n b} ;}{b_{3}=\frac{\frac{\left(1,5-\rho_{a}\right)}{n} \hat{\sigma}_{a}^{2}}{\hat{\sigma}_{d p}^{2} / n+\hat{\sigma}_{c}^{2}} ;}
\end{gathered}
$$

$\rho_{a}$ : correlação genética aditiva intraclasse $\left(\rho_{a}\right.$ $=1$ neste caso, por ter sido considerado que essas pro- gênies se comportam, quanto à quantidade de variação genética entre e dentro, como de autofecundação $\left(S_{1}\right)$.

$\hat{\sigma}_{f a}^{2}, \hat{\sigma}_{c}^{2} \mathrm{e} \hat{\sigma}_{d p}^{2}$ : variância entre famílias, entre parcelas e dentro de parcelas, respectivamente.

$Y_{i j k}, \bar{Y}_{i j .}, \bar{Y}_{i . .}$, e $\bar{Y}_{\ldots}$ : valor fenotípico individual, média da parcela, média da progênie, média do bloco e média geral respectivamente.

Estimadores iterativos dos componentes de variância por REML via algoritmo EM.

$$
\begin{aligned}
& \hat{\sigma}_{e}^{2}=\left[y^{\prime} y-\hat{b}^{\prime} X^{\prime} y-\hat{a}^{\prime} Z^{\prime} y-\hat{c}^{\prime} W^{\prime} y\right][N-r(x)] \\
& \hat{\sigma}_{a}^{2}=\left[\hat{a}^{\prime} A^{-1} \hat{a}+\hat{\sigma}_{e}^{2} \operatorname{tr}\left(A^{-1} C^{22}\right)\right] q \\
& \hat{\sigma}_{c}^{2}=\left[\hat{c}^{\prime} c+\hat{\sigma}_{e}^{2} \operatorname{tr} C^{33}\right] s, \text { em que: } \\
& C^{22} \text { e } C^{33} \text { advêm de: }
\end{aligned}
$$$$
C^{-1}=\left[\begin{array}{lll}
C_{11} & C_{12} & C_{13} \\
C_{21} & C_{22} & C_{23} \\
C_{31} & C_{32} & C_{33}
\end{array}\right]^{-1}=\left[\begin{array}{lll}
C^{11} & C^{12} & C^{13} \\
C^{21} & C^{22} & C^{23} \\
C^{31} & C^{32} & C^{33}
\end{array}\right]
$$

C: matriz dos coeficientes das equações de modelo misto.

tr: operador traço matricial.

$\mathrm{r}(\mathrm{x})$ : posto da matriz $\mathrm{X}$.

$\mathrm{N}$, q, s: número total de dados, de indivíduos e de parcelas, respectivamente.

\section{RESULTADOS E DISCUSSÃO}

A análise da existência de variabilidade genética, por meio da herdabilidade individual no sentido restrito (Tabela 1), demonstra que para os caracteres maturação dos frutos, tamanho e produtividade de grãos não há condições favoráveis para a seleção, já que os valores baixos desses parâmetros apresentados indicam a existência de pouca de variabilidade genética. São resultados esperados considerando que os parentais utilizados para a obtenção dessas progênies são linhagens em geração avançada com produtividades de grãos altas e tamanhos dos grãos e maturação dos frutos semelhantes.

As progênies apresentaram para resistência à ferrugem o valor de 0,6082 para herdabilidade de média de progênies e de 0,3214 para herdabilidade individual no sentido restrito (Tabela 1) demonstrando a existência de alta variabilidade. A possibilidade de sucesso na seleção destas progênies 
é visualizada principalmente na herdabilidade individual no sentido restrito o qual é relacionada aos efeitos aditivos. Estes efeitos são aqueles herdáveis na seleção para obtenção de cultivares do tipo linhagens propagadas por semente, possuidoras de resistência qualitativa à ferrugem oriunda do parental "Sarchimor" PR75163-7 e simultaneamente com resistência quantitativa originária do ("Icatu" $\mathrm{x}$ "Catuaí") MRFPB-C-41-1.
O coeficiente de variação genética aditiva individual de 8,4162 \% (Tabela 1) comprova a situação propícia para a seleção de indivíduos com maior valor individual aditivo para resistência à ferrugem, e o valor de 0,8810 para o coeficiente de variação relativa $\left(C V_{r}=\right.$ $C V_{g p}(\%) / C V_{\mathrm{e}}(\%)$ indica situação propícia para a seleção entre progênies, já que a herdabilidade de médias de progênie equivaleu a 0,6082 , fato que conduz a uma acurácia seletiva de 0,7799 (78\%), a qual é alta.

Tabela 1. Parâmetros genéticos estimados para resistência à ferrugem $(\mathrm{F})$, vigor vegetativo (V), maturação dos frutos (M), tamanho dos grãos (TG) e potencial de produtividade (P) a partir da metodologia REML e a média das progênies para cada caráter

\begin{tabular}{lcccrr}
\hline Parâmetros & $\mathrm{F}$ & $\mathrm{V}$ & $\mathrm{M}$ & $\mathrm{TG}$ & $\mathrm{P}$ \\
\hline$\hat{\sigma}_{g a}^{2}$ & 0,1298 & 0,0154 & 0,0031 & 0,0002 & 0,3299 \\
$\hat{\sigma}_{f i}^{2}$ & 0,7255 & 0,2471 & 0,1418 & 0,0429 & 184,3794 \\
$\hat{\sigma}_{e p}^{2}$ & 0,1197 & 0,0361 & 0,0173 & 0,0019 & 4,6193 \\
$\hat{\sigma}_{e}^{2}$ & 0,4760 & 0,1955 & 0,1214 & 0,0407 & 179,4302 \\
$\hat{h}_{i a p}^{2}$ & 0,3214 & 0,1906 & 0,0371 & 0,0087 & 0,0027 \\
$\hat{h}_{p}^{2}$ & 0,6082 & 0,3567 & 0,1728 & 0,0737 & 0,0284 \\
$C V_{G I A}(\%)$ & 8,4162 & 1,7899 & 1,7502 & 0,5646 & 1,4942 \\
$C V_{G P}(\%)$ & 8,4150 & 1,7878 & 1,7334 & 0,5036 & 1,1141 \\
$C V_{E}(\%)$ & 9,5516 & 3,3956 & 5,3631 & 2,5258 & 9,2136 \\
$C V_{r}$ & 0,8810 & 0,5265 & 0,3232 & & 0,1994 \\
Média & 4,2818 & 6,9462 & 3,2006 & 3,0670 & 51,5539 \\
\hline
\end{tabular}

$\hat{\sigma}_{g a}^{2}$ : variância genética aditiva; $\hat{\sigma}_{f i}^{2}:$ variância fenotípica individual; $\hat{\sigma}_{e p}^{2}$ : variância ambiental entre parcelas; $\hat{\sigma}_{e}^{2}:$ variância residual (ambiental + não aditiva); $\hat{h}_{p}^{2}$ : herdabilidade individual, no sentido restrito, ajustado para efeito de parcela; $\hat{h}_{p}^{2}$ herdabilidade de média de progênies; $C V_{g i a}(\%)$ : coeficiente de variação genética aditiva individual; $C V_{g p}(\%)$ : coeficiente de variação genética entre progênies; $C V_{e}(\%)$ : coeficiente de variação residual; $C V_{r}(\%)=\mathrm{CV}_{\mathrm{gp}}(\%) / \mathrm{CV}_{\mathrm{e}}(\%)$ : coeficiente de variação relativa.

Para o caráter vigor vegetativo as progênies apresentaram valor para a herdabilidade no sentido restrito de 0,1096 e para a herdabilidade de médias de progênies foi 0,3567 (Tabela 1). Esses valores indicam possibilidades de sucesso com a seleção entre e dentro de progênies. Porém, o valor apresentado para o coeficiente de variação relativo $\left(C V_{r}=C V_{g p}(\%) / C V_{e}(\%)\right.$ de 0,5265 indica baixa possibilidade de sucesso com a seleção entre progênies, visto que esse parâmetro mostra que a variação ambiental entre as progênies é bem maior que a variação genética em relação à média.

Com a não-detecção de variabilidade genética nessas progênies para tamanho dos grãos (TG), maturação dos frutos (M) e produtividade de grãos $(\mathrm{P})$ e considerando a variabilidade verificada para resistência à ferrugem $(\mathrm{F})$, vigor vegetativo $(\mathrm{V})$, inclusive indicando a maior possibilidade de sucesso na seleção de indivíduos e não de progênies, optou-se por realizar a seleção de indivíduos mediante efeito genético aditivo individual (â) (Tabela 2) para esses dois caracteres. Na seleção, a prioridade foi para indivíduos com maior efeito genético aditivo para vigor vegetativo e posteriormente para resistência à ferrugem, com intensidade de seleção de $10 \%$, posto que o ganho genético para vigor vegetativo será mais dificultado pela menor variabilidade existente (Tabela 2).

Foram selecionados nove indivíduos da progênie 14 , oito da progênie 10 , seis da progênie 9 , cinco das progênies 4,1 e 11, quatro da progênie 7,2 da progênie 17 e um indivíduo de cada uma das progênies 25, 13, 27, 5, 22, 21, 24, 12, 8 e 16 . Portanto, foram selecionados 54 indivíduos dentro da população total com os maiores valores genéticos aditivos para vigor vegetativo e também com efeito genético aditivo positivo para resistência à ferrugem (Tabela 2). É importante ressaltar que a seleção a partir do efeito genético aditivo facilita a obtenção de plantas superiores, pois foram descartadas plantas com valores fenotípicos maiores que as selecionadas. 
Tabela 2. Valor fenotípico (f), efeito aditivo (â) e valor genético aditivo ( $\hat{u}+\hat{a})$ predito para 54 plantas selecionadas, o Ganho Genético Aditivo Predito (efeito aditivo médio das 54 plantas selecionadas) e a média melhorada predita (valor genético aditivo médio das 54 plantas selecionadas) para os caracteres vigor vegetativo (V) e resistência à ferrugem (F).

\begin{tabular}{|c|c|c|c|c|c|c|c|c|}
\hline \multirow{2}{*}{ Progênie } & \multirow{2}{*}{ Bloco } & \multirow{2}{*}{ Planta } & \multicolumn{3}{|c|}{$\mathrm{V}$} & \multicolumn{3}{|c|}{$\mathrm{F}$} \\
\hline & & & $\mathrm{f}$ & $\hat{a}$ & $\hat{\mathrm{u}}+\hat{\mathrm{a}}$ & $\mathrm{f}$ & $\hat{a}$ & $\hat{\mathrm{u}}+\hat{\mathrm{a}}$ \\
\hline 9 & 1 & 7 & 8,67 & 0,4451 & 7,3913 & 5,00 & 0,3927 & 4,6746 \\
\hline 14 & 1 & 3 & 8,67 & 0,4433 & 7,3895 & 5,00 & 0,6375 & 4,9193 \\
\hline 10 & 1 & 7 & 8,67 & 0,4405 & 7,3867 & 4,00 & 0,0423 & 4,3242 \\
\hline 4 & 1 & 6 & 8,67 & 0,3942 & 7,3404 & 5,00 & 0,4966 & 4,7784 \\
\hline 14 & 1 & 7 & 8,33 & 0,3644 & 7,3107 & 5,00 & 0,6375 & 4,9193 \\
\hline 14 & 2 & 10 & 7,67 & 0,3219 & 7,2681 & 5,00 & 0,4860 & 4,7679 \\
\hline 4 & 1 & 7 & 8,33 & 0,3153 & 7,2616 & 5,00 & 0,4966 & 4,7784 \\
\hline 1 & 2 & 5 & 8,00 & 0,3043 & 7,2506 & 5,00 & 0,5322 & 4,8141 \\
\hline 9 & 1 & 5 & 8,00 & 0,2874 & 7,2336 & 5,00 & 0,3927 & 4,6746 \\
\hline 14 & 1 & 4 & 8,00 & 0,2856 & 7,2318 & 5,00 & 0,6375 & 4,9193 \\
\hline 10 & 1 & 10 & 8,00 & 0,2828 & 7,2290 & 4,00 & 0,0423 & 4,3242 \\
\hline 10 & 2 & 6 & 7,67 & 0,2771 & 7,2233 & 5,00 & 0,3580 & 4,6398 \\
\hline 10 & 2 & 8 & 7,67 & 0,2771 & 7,2233 & 5,00 & 0,3580 & 4,6398 \\
\hline 9 & 2 & 8 & 7,67 & 0,2638 & 7,2100 & 4,00 & 0,0670 & 4,3489 \\
\hline 25 & 1 & 1 & 8,00 & 0,2345 & 7,1807 & 5,00 & 0,7440 & 5,0259 \\
\hline 13 & 2 & 5 & 8,00 & 0,2246 & 7,1708 & 5,00 & 0,8026 & 5,0844 \\
\hline 17 & 2 & 1 & 8,00 & 0,2224 & 7,1686 & 5,00 & 0,4504 & 4,7322 \\
\hline 17 & 2 & 2 & 8,00 & 0,2224 & 7,1686 & 5,00 & 0,4504 & 4,7322 \\
\hline 11 & 1 & 1 & 8,00 & 0,2113 & 7,1575 & 5,00 & 0,4028 & 4,6847 \\
\hline 11 & 1 & 10 & 8,00 & 0,2113 & 7,1575 & 5,00 & 0,4028 & 4,6847 \\
\hline 7 & 2 & 5 & 7,67 & 0,2100 & 7,1562 & 5,00 & 0,5213 & 4,8031 \\
\hline 7 & 2 & 9 & 7,67 & 0,2100 & 7,1562 & 5,00 & 0,5213 & 4,8031 \\
\hline 9 & 1 & 6 & 7,67 & 0,2086 & 7,1548 & 5,00 & 0,3927 & 4,6746 \\
\hline 14 & 1 & 9 & 7,67 & 0,2067 & 7,1530 & 5,00 & 0,6375 & 4,9193 \\
\hline 27 & 1 & 2 & 7,67 & 0,2055 & 7,1517 & 4,00 & 0,0419 & 4,3237 \\
\hline 10 & 1 & 1 & 7,67 & 0,2040 & 7,1502 & 4,00 & 0,0423 & 4,3242 \\
\hline 10 & 1 & 4 & 7,67 & 0,2040 & 7,1502 & 4,00 & 0,0423 & 4,3242 \\
\hline 10 & 2 & 7 & 7,33 & 0,1982 & 7,1445 & 5,00 & 0,3580 & 4,6398 \\
\hline 10 & 2 & 10 & 7,33 & 0,1982 & 7,1445 & 5,00 & 0,3580 & 4,6398 \\
\hline 5 & 1 & 5 & 7,67 & 0,1911 & 7,1374 & 5,00 & 0,5794 & 4,8612 \\
\hline 22 & 1 & 5 & 7,67 & 0,1870 & 7,1332 & 5,00 & 0,3914 & 4,6732 \\
\hline 21 & 1 & 6 & 7,67 & 0,1861 & 7,1324 & 4,00 & 0,0789 & 4,3608 \\
\hline 9 & 2 & 5 & 7,33 & 0,1849 & 7,1312 & 4,00 & 0,0670 & 4,3489 \\
\hline 7 & 1 & 7 & 7,67 & 0,1727 & 7,1189 & 5,00 & 0,6141 & 4,8960 \\
\hline 7 & 1 & 8 & 7,67 & 0,1727 & 7,1189 & 5,00 & 0,6141 & 4,8960 \\
\hline 14 & 2 & 3 & 7,00 & 0,1642 & 7,1104 & 5,00 & 0,4860 & 4,7679 \\
\hline 14 & 2 & 7 & 7,00 & 0,1642 & 7,1104 & 5,00 & 0,4860 & 4,7679 \\
\hline 14 & 2 & 9 & 7,00 & 0,1642 & 7,1104 & 5,00 & 0,4860 & 4,7679 \\
\hline 1 & 1 & 1 & 7,67 & 0,1600 & 7,1063 & 5,00 & 0,5080 & 4,7899 \\
\hline 1 & 1 & 9 & 7,67 & 0,1600 & 7,1063 & 5,00 & 0,5080 & 4,7899 \\
\hline 1 & 1 & 10 & 7,67 & 0,1600 & 7,1063 & 5,00 & 0,5080 & 4,7899 \\
\hline 4 & 1 & 2 & 7,67 & 0,1577 & 7,1039 & 5,00 & 0,4966 & 4,7784 \\
\hline 24 & 1 & 3 & 7,67 & 0,1534 & 7,0997 & 5,00 & 0,6018 & 4,8836 \\
\hline 4 & 2 & 8 & 7,33 & 0,1519 & 7,0982 & 5,00 & 0,5794 & 4,8612 \\
\hline 4 & 2 & 9 & 7,33 & 0,1519 & 7,0982 & 5,00 & 0,5794 & 4,8612 \\
\hline 1 & 2 & 8 & 7,33 & 0,1466 & 7,0929 & 5,00 & 0,5322 & 4,8141 \\
\hline 12 & 1 & 5 & 7,67 & 0,1366 & 7,0828 & 5,00 & 0,6375 & 4,9193 \\
\hline 8 & 2 & 9 & 7,67 & 0,1361 & 7,0823 & 5,00 & 0,4170 & 4,6988 \\
\hline 16 & 2 & 2 & 7,33 & 0,1352 & 7,0815 & 5,00 & 0,3918 & 4,6737 \\
\hline 11 & 2 & 3 & 7,33 & 0,1341 & 7,0803 & 5,00 & 0,6612 & 4,9431 \\
\hline 11 & 1 & 6 & 7,67 & 0,1324 & 7,0786 & 5,00 & 0,4028 & 4,6847 \\
\hline 11 & 1 & 7 & 7,67 & 0,1324 & 7,0786 & 5,00 & 0,4028 & 4,6847 \\
\hline 9 & 1 & 8 & 7,33 & 0,1297 & 7,0759 & 5,00 & 0,3927 & 4,6746 \\
\hline 14 & 1 & 8 & 7,33 & 0,1279 & 7,0741 & 5,00 & 0,6375 & 4,9193 \\
\hline \multicolumn{3}{|c|}{ Média de plantas selecionadas } & 7,73 & 0,2179 & 7,1641 & 4,85 & 0,4408 & 4,7226 \\
\hline \multicolumn{3}{|c|}{ Ganho genético aditivo predito } & & 0,2179 & & & 0,4408 & \\
\hline \multicolumn{3}{|c|}{ Ganho genético aditivo predito (\%) } & & 3,14 & & \multirow{2}{*}{\multicolumn{2}{|c|}{10,29}} & \\
\hline \multicolumn{3}{|c|}{ Média melhorada predita } & \multirow{2}{*}{\multicolumn{3}{|c|}{6,9462}} & & & 4,7226 \\
\hline \multicolumn{3}{|c|}{ Média das progênies } & & & & 4,281 & & \\
\hline Média da & $59^{\prime}$ & & 7,036 & & & 4,700 & & \\
\hline
\end{tabular}


Com a utilização de outros métodos, como a estimação de parâmetros com base na análise de variância, essas plantas seriam selecionadas, porque não separam os efeitos genéticos aditivos de cada individuo e a seleção é feita pelo valor fenotípico.

A seleção das 54 plantas $(10 \%$ de intensidade de seleção) com média do valor fenotípico de 7,73 para vigor vegetativo, proporcionou ganho genético aditivo predito de 0,2179 , ou seja, de $3,14 \%$. A média melhorada predita com os efeitos aditivos (valor genético aditivo médio) é de 7,1641 , superior à média (valor fenotípico) da testemunha 'IAPAR 59' que foi de 7,0361 .

As mesmas plantas tiveram valor fenotípico médio de 4,85 para resistência à ferrugem, proporcionando ganho genético aditivo predito de 0,4408 , o que significa $10,29 \%$ de ganho, ou seja, a média melhorada predita para efeitos aditivos de 4,7226, semelhante à 'IAPAR 59', considerada resistente a todas as raças de ferrugem presentes no Brasil.

Portanto, a seleção destas 54 progênies proporcionará ganhos simultâneos de $3,14 \%$ para vigor vegetativo e de $10,29 \%$ para resistência à ferrugem, possibilitando a obtenção de linhagens a partir desta população com vigor vegetativo superior à 'IAPAR $59^{\prime}$ e possuindo resistência à ferrugem mais próxima da 'IAPAR 59'. Também é importante que esta população seja mantida, devido à alta variabilidade existente para resistência à ferrugem, com o objetivo de re-selecionar progênies caso ocorra o aparecimento de novas raças de $H$. vastatrix quebrando a resistência das linhagens mais avançadas com menos genes de resistência. A obtenção de cultivares derivadas de "Sarchimor" com melhor vigor vegetativo é importantante, pois esta característica é correlacionada com produtividade de grãos (Severino, et al., 2002; PeteK et al., 2002), com menor vulnerabilidade às condições edafoclimáticas desfavoráveis (PeteK et al., 2002; Sera et al., 2002) e proporciona menor incidência de "die back", além de diminuir os problemas de queda do vigor vegetativo e diminuição da longevidade dos cafeeiros, normalmente associados as cultivares derivadas de "Sarchimor" e "Catimor" (Matiello et al., 2005).

É importante ressaltar que o sistema de plantio e manejo pode amenizar e até solucionar os problemas de queda de vigor, devido a cargas excessivas nos primeiros anos, de cultivares como a 'IAPAR 59'. No Paraná, o Modelo IAPAR de Café Adensado preconiza o aumento de produtividade por área, pelo aumento da densidade de plantas, em conjunto com adubação suficiente, proporcionando menor produção por cafeeiro; conseqüentemente, diminui o esgotamento nutricional e mantém o vigor, entre outros objetivos, sendo bom exemplo de como o manejo pode auxiliar na solução deste problema.

\section{CONCLUSÕES}

1. A partir da população derivada do cruzamento "Sarchimor" PR75163-7 x ("Icatu" x "Catuaí") MRFPB-C-41-1, é possível a obtenção de linhagens superiores com resistência à ferrugem e alto vigor vegetativo.

2. A seleção de plantas individuais a partir do efeito genético aditivo, predito pelo método REML/ BLUP facilita a escolha dos indivíduos geneticamente melhores e, conseqüentemente, promove a maximização do ganho genético por ciclo de seleção.

\section{AGRADECIMENTOS}

À equipe de Melhoramento Genético de Café do Instituto Agronômico do Paraná (IAPAR) por propiciarem o desenvolvimento dos trabalhos. Ao Consórcio Brasileiro de Pesquisa e Desenvolvimento do Café e à Coordenação de Aperfeiçoamento de Pessoal de Nível Superior (CAPES) pelo apoio financeiro. Ao Programa de Pós-Graduação em Agronomia da Universidade Estadual de Londrina.

\section{REFERÊNCIAS}

FAZUOLI, L. C. Avaliação de progênies de café Mundo Novo (Coffea arabica L.). 1977. Tese (doutorado) - Escola Superior de Agricultura "Luiz de Queiroz", Universidade de São Paulo, Piracicaba.

FAZUOLI, L. C.; MEDINA-FILHO, H. P.; GONÇALVES, W.; GUERREIRO FILHO, O.; SILVAROLLA, M. B. Melhoramento do Cafeeiro: Variedades Tipo Arábica Obtidas no Instituto Agronômico de Campinas. In: ZAMBOLIM L. (Ed.). O estado da arte de tecnologias na produção de café. Viçosa: UFV, 2002. p. 163-216.

FAZUOLI, L.C.; OLIVEIRA, A.C.B..; BRAGHINI, M.T.; SILVAROLLA, M.B. Identification and use of sources of durable resistance to coffee leaf rust at the IAC. In: ZAMBOLIM, L.; ZAMBOLIM, E.M.; VÁRZEA, V.M.P. Durable Resistance to Coffee Leaf Rust. Viçosa: UFV, 2005. p.137-186.

GARCIA, C.H.; NOGUEIRA, M.C.S. Utilização da metodologia REML/BLUP na seleção de clones de eucalipto. Scientia Forestalis, v.68, p.107-112. 2005.

MATIELLO, J.B.; ALMEIDA, S.R.; CARVALHO, C.H.S. Resistant cultivars to coffee leaf rust. In: ZAMBOLIM, L.; ZAMBOLIM, E.M.; VÁRZEA, V.M.P. Durable Resistance to Coffee Leaf Rust. Viçosa: UFV, 2005. p.443-445. 
MISSIO, R.F.; DIAS, L.A.S.; MORAES, M.L.T.; RESENDE, M.D.V. Selection of Pinus caribaea var. bahamensis progênies based on the predicted genetic value. Crop Breeding and Applied Biotechnology, v.4, p.399-407. 2004.

FARIAS NETO, J.T.; RESENDE, M.D.V. Aplicação da metodologia de modelos mistos (REML/BLUP) na estimação de componentes de variância e predição de valores genéticos em pupunheira (Bactris gasipaes). Revista Brasileira de Fruticultura, v.23, n.2, p. 22-52. 2001.

PEREIRA, A. A.; MOURA, W. M.; ZAMBOLIM, L.; SAKIYAMA, N. S.; CHAVES, G. M. Melhoramento Genético do Cafeeiro no Estado de Minas Gerais - cultivares lançados e em fase de obtenção. In: ZAMBOLIM, L (Ed.). O estado da arte de tecnologias na produção de café. Viçosa: UFV, 2002. p. 253-296.

PEREIRA, A. A.; SAKIYAMA, N. S.; ZAMBOLIM, L.; MOURA, W. M.; ZAMBOLIM, E.M.; CAIXETA, E.T. Identification and use of sources of durable resistance to coffee leaf rust in the UFV / EPAMIG breeding program. In: ZAMBOLIM, L.; ZAMBOLIM, E.M.; VÁRZEA, V.M.P. Durable Resistance to Coffee Leaf Rust. Viçosa: UFV, 2005. p.215-232.

PETEK, M.R.; SERA, T.; ALTÉIA, M.Z.; AZEVEDO, J.A.; TRILLER, C.; FADELLI, S. Análise de trilha entre caracteres agronômicos e dano de geada, em progênies derivadas do cruzamento "Vila Sarchi" x "Híbrido de Timor". SBPN Scientific Journal, v. 6, p.37-39, 2002. (Ed. Especial)

RESENDE, M.D.V. Genética biométrica e estatística no melhoramento de plantas perenes. Colombo: EMBRAPA Floresta; Brasília: Informação Tecnológica, 2002. 975p.

RESENDE, M.D.V. O software selegen - REML/BLUP. Campo Grande: EMBRAPA, 2006. 299p.
RESENDE, M.D.V.; FURLANI-JUNIOR, E.; MORAES, M.L.T.; FAZUOLI, L.C. Estimação de parâmetros genéticos e predição de valores genotípicos no melhoramento do cafeeiro pelo procedimento REML/BLUP. Bragantia, Campinas, v.60, p.185193. 2001.

SERA T. Coffee genetic breeding at Iapar. Crop Breeding and Applied Biotechnology, Londrina, v.1, n.2, p.179-200. 2001.

SERA, T.; ALTEIA, M. Z.; PETEK, M.R. Melhoramento do Cafeeiro: Variedades Melhoradas no Instituto Agronômico do Paraná (IAPAR). In: ZAMBOLIM L (Ed.). O estado da arte de tecnologias na produção de café. Viçosa: UFV, 2002. p.217-251.

SERA, T.; SERA, G.H; ITO, D.S.; DOI, D.S. Coffee breeding for durable resistance to leaf rust disease at Instituto Agronômico do Paraná. In: ZAMBOLIM, L.; ZAMBOLIM, E.M.; VÁRZEA, V.M.P. Durable Resistance to Coffee Leaf Rust. Viçosa: UFV, 2005. p.187-214.

SEVERINO, L.S.; SAKIYAMA, N.S.; PEREIRA, A. A.; MIRANDA, G.V.; ZAMBOLIM, L.; BARROS, U.V. Associações da produtividade com outras características agronômicas de café (Coffea arabica L. "Catimor"). Acta Scientiarum, v.24, n.5, p.1467-1471. 2002.

VÁRZEA, V.M.P.; RODRIGUES Jr, C.J.; SILVA, M.C.M.L.; GOUVEIA, M.; MARQUES, D.V.; GUERRA-GUIMARÃES, L.; RIBEIRO, A. Resistência do cafeeiro a Hemileia vastatrix. In: ZAMBOLIM, L. O estado da arte de tecnologias na produção de café. Viçosa: UFV, 2002. p.297-320.

VÁRZEA, V.M.P.; MARQUES, D.V. Population variability of Hemileia vastatrix vs. coffee durable resistance. In: ZAMBOLIM, L.; ZAMBOLIM, E.M.; VÁRZEA, V.M.P. Durable Resistance to Coffee Leaf Rust. Viçosa: UFV, 2005. p.53-74. 